\title{
THE CFD METHOD-BASED RESEARCH ON DAMAGED SHIP'S FLOODING PROCESS IN TIME-DOMAIN
}

\author{
Hu Li-Fen ${ }^{1}$ \\ Qi Huibo ${ }^{1}$ \\ Li Yuemeng ${ }^{2}$ \\ Li Wubin ${ }^{1}$ \\ Chen Shude ${ }^{1}$ \\ ${ }^{1}$ Communications of Institute, Ludong University, Yantai, China \\ ${ }^{2}$ Ulsan Ship and Ocean College, Ludong University, Yantai, China
}

\begin{abstract}
The flooding process is one of the main concerns of damaged ship stability. This paper combines the volume of fluid (VOF) method incorporated in the Navier-Stokes (NS) solver with dynamic mesh techniques to simulate the flooding of a damaged ship. The VOF method is used to capture the fluid interface, while the dynamic mesh techniques are applied to update the mesh as a result of transient ship motions. The time-domain flooding processes of a damaged barge and a rectangular cabin model are carried out based on the abovementioned method, and the computational results appear compatible with the experimental data. During the flooding process, the motion of the flooding flow at different stages is observed and compared with that observed in real conditions. The time-domain research of the flooding process is the starting point for subsequent establishment of damaged ship's roll movement and capsizing the mechanism of dead ship condition in wave.
\end{abstract}

Keywords: flooding process; Bernoulli equation; time domain calculation; damaged ship

\section{INTRODUCTION}

Nowadays, ship damages caused by collision and grounding provide serious threat to their life and safety, and even to the environment. When the ship is damaged, water starts to flow through the created opening to the ship hull. Sometimes, the progressive course of flooding may take a very long time, and the intermediate flooding stages can be more dangerous than the final equilibrium state. Nowadays, the International Maritime Organization (IMO) has also requirements concerning the damaged ship stability during intermediate flooding stages (IMO, 2008). In this context, the simulation of the intermediate flooding process is of utmost importance for ship stability.

The time-domain based flooding simulation tools have been significantly developed during recent years (Santos, 2002; Vassalos, 2004; Ruponen, 2007\&2012; Lee, 2007; Tiago, 2008\&2009; Ypma, 2010; Schreuder, 2011; Lemoine, 2013). The available flooding investigation methods include: model test, quasi-static method based on Bernoulli equation, meshless method, Computational Fluid Dynamics (CFD) simulation based on Navier-Stokes equations, etc. The increased calculating capacity has made the time-domain simulation possible even for complex damage stability analyses (Ruponen, 2017; Manderbacka, 2015\&2016).

This paper carries out the flooding simulation research based on Navier-Stokes equations and CFD technology. The magnitude and phase of the dynamic roll moment caused by the water in the compartment are investigated employing the six degrees of freedom motion solution and the dynamic mesh strategy. In the reported study, a solver which combines the NS equations with the Volume of Fluid (VOF) model was adopted to simulate the coupled motion of the damaged ship and floodwater. The progressive course of flooding is predicted using the time-domain flooding simulation method described in the article. The applied method is based on the law of conservation of mass and the Bernoulli equation. To test the applied method, the developed solver was used to investigate 
the flooding process of a damaged barge and a rectangular cabin model. The numerical results were compared with the experimental data, and this comparison has proved that the adopted method can successfully simulate the interactive dynamics between the ship and floodwater, as well as predict the ship's floating position. All simulations were conducted on a core-processor (Intel Core2, 3.0GHz) server.

\section{MATHEMATICAL MODEL}

\section{GOVERNING EQUATIONS OF FLUID MOTION}

The incompressible flow of two different fluids (water and air) (Li, 2016) is considered. Based on this assumption, the differential forms of the NS equation and the continuity equation are as follows:

Continuity equation:

$$
\frac{\partial \overline{u_{i}}}{\partial \overline{x_{i}}}=0
$$

RANS equation:

$\rho \frac{\partial \bar{u}_{i}}{\partial t}+\rho \overline{u_{j}} \frac{\partial \bar{u}_{i}}{\partial x_{j}}=-\frac{\partial \bar{p}}{\partial x_{i}}+\mu \frac{\partial^{2} \overline{u_{i}}}{\partial x_{j} \partial x_{j}}-\rho \frac{\partial \overline{u_{i}^{\prime} u_{j}^{\prime}}}{\partial x_{j}}+\rho \overline{f_{i}}$

In these equations, $\bar{u}_{i}$ is the dynamic viscosity $\rho \overline{u_{i}^{\prime} u_{j}^{\prime}}$, is the Reynolds stress, $\rho$ is the density of fluid, $v$ is the fluid viscosity, $p$ is the pressure, $\rho=\alpha \rho_{1}+(1-\alpha) \rho_{2}$ is the effective density, $\rho_{1}$ and $\rho_{2}$ are the densities of water and air, respectively, $v=\alpha \mu_{1}+(1-\alpha) \mu_{2}$ is the effective viscosity, $\mu_{1}$ and $\mu_{2}$ are the viscosity of water and air, respectively, and $\alpha$ is the fluid volume fraction. Both fluids: water and air, are considered incompressible.

\section{FREE SURFACE CAPTURING METHOD}

The VOF (Gao, 2010) method is used to capture the free surface. This method is a surface tracking method fixed under the Euler grid. It simulates the multiphase flow model by solving the momentum equation and the volume fraction of one or more fluids. Within each control volume, the sum of the volume fractions of all the phases is 1 . As to Phase $q$, its equation is:

$$
\frac{\partial a_{q}}{\partial t}+\frac{\partial\left(u a_{q}\right)}{\partial x}+\frac{\partial\left(v a_{q}\right)}{\partial y}+\frac{\partial\left(w a_{q}\right)}{\partial z}=0
$$

where $\mathrm{a}_{1}$ and $\mathrm{a}_{2}$ are, respectively, the volume fractions of air and water, and $\mathrm{a}_{q}=0.5$ is the air/water interface. $q=0$ means that the unit is filled with water, while $q=1$ means that the unit is filled with air. In the present study, the turbulence effect on the flows is not considered, and the laminar flow model is adopted in the simulations which will be discussed in Section 4.1.

\section{GOVERNING EQUATIONS OF RIGID BODY MOTION}

The rigid body motion can be evaluated from the following equations:

$$
\begin{aligned}
& \frac{d P}{d t}=F \\
& \frac{d \pi}{d t}=m
\end{aligned}
$$

These equations explain that for a rigid body undergoing translation and rotation, the rate of change of the linear and angular momentum of the rigid body, $P$ and $\pi$ respectively, is equal to the applied force $F$ and torque $m$ acting on the body.

\section{EQUATION OF PROGRESSIVE FLOODING}

During the past decades, the time-domain flooding simulations have mainly been based on a hydraulic model, using the Bernoulli equation and conservation of mass. Nowadays, the simulation is already a well-established approach to study the details of a damage case and a valuable tool for accident investigations.

In the majority of damaged model investigations, the simple hydraulic model referred to as the orifice equation is used. This model can be drawn from the Bernoulli equation for steady flow (Lyu, 2015). For a streamline from point A in the damaged tank to point B in the outlet of the cross-duct, the Bernoulli equation can be written as:

$$
\frac{1}{2 g} v_{1}^{2}+\frac{p_{1}}{\rho g}+h_{1}=\frac{1}{2 g} v_{2}^{2}+\frac{p_{2}}{\rho g}+h_{2}
$$

Considering conservation of energy, the flow velocity at the damaged opening is:

$$
v_{2}=\sqrt{2 g\left(h_{1}-h_{2}\right)}
$$

where $v_{2}$ is the flow velocity at the damaged opening, $h_{1}$ is the vertical distance between the extra waterline and the centerline of the damaged opening, $h_{2}$ is the vertical distance between the cabin waterline and the centerline of the damaged opening, and $g$ is the acceleration due to gravity.

Considering the flooding process in the time domain, the volumetric flow through the opening with area $A$ is:

$$
\begin{gathered}
t_{\mathrm{a} 11}=\int_{0}^{v} \frac{1}{C_{d} A \sqrt{2 g\left(h_{1}-h_{2}\right)}} d V \\
d V=Q \cdot d t=C_{d} A \sqrt{2 g\left(h_{1}-h_{2}\right)} d t \\
V=\sum d V
\end{gathered}
$$

where $Q$ is the flow rate through the opening at a given time, $A$ is the area of the damaged opening, $V$ is the volume of the flooding water, $t_{\mathrm{a}||}$ is the summation of each time step, and $C_{d}$ is the discharge coefficient which takes into consideration 
waves, sloshing, etc. The flow rate $Q$ is obtained by integration over the area of the opening.
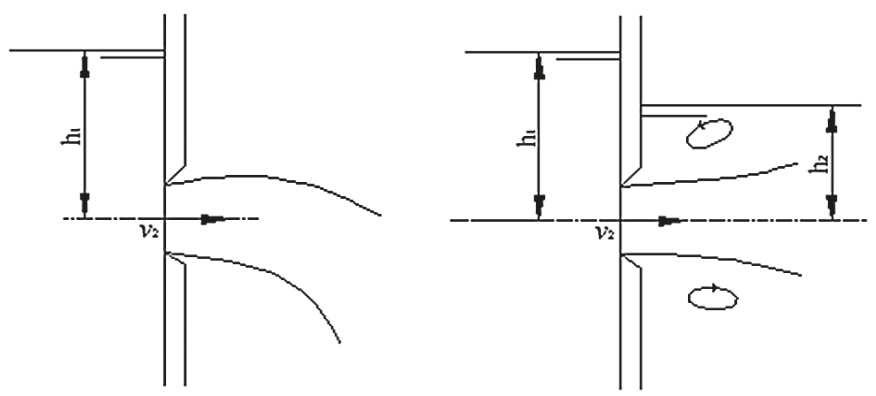

Fig. 1. Flow through the orifice

At each time step, the water levels in the flooded rooms are solved iteratively to satisfy the conservation of mass, and the flow velocities in the openings are solved by applying the Bernoulli theorem. A constant discharge coefficient 0.6 is used for all openings. The sea is assumed to be calm and the ship motions are considered to be fully quasi-stationary.

\section{NUMERICAL METHOD}

The equations (1)-(3) are analyzed using the finite volume method to simulate the fluid field. The SIMPLE algorithm is employed in the pressure-based solver, which is mainly used for incompressible fluid fields. For the coupling movement during the flooding process, this paper adopts a six degrees of freedom solver and the dynamic mesh strategy with rigid boundaries.

\section{DYNAMIC MESH STRATEGY}

As the surface is part of the boundary of the fluid, it is necessary to dynamically update the grid according to the geometric change of the fluid domain caused by the body motion during the calculation process. In the paper, the dynamic mesh strategy is applied to update the mesh. By means of this strategy, the mesh is automatically deformed, including changes of the region boundary geometry, at the same time keeping its topology constant. The computational domain contains floodable compartments and the external flow region near the damaged section of the ship, as shown in Fig. 2. The computational domain is divided into three regions, labelled as region 1, region 2 and region 3 . Region 1 experiences the same translational and rotational motion as the body, and, consequently, the mesh of this region could be shifted without geometrical and topological changes, which includes ship hull and adjacent hull part. Using this strategy, the optimum mesh quality is maintained during the calculation. Region 2 is the buffer, in which the mesh is automatically deformed following the change of the region boundary geometry, while keeping its topology constant. Region 3 is the fixed region, in which the mesh is kept static throughout the simulation. This approach makes it easier to meet specific boundary conditions along the outer boundaries.

\section{CONVERGENCE JUDGEMENT}

The time step adopted in this paper is assumed to meet the cell Courant number $C(\mathrm{Li}, 2016)$ within a limit value of 10 .

$$
C=\Delta t / \min (\Delta x / u) \leq C_{\lim }
$$

where: $\Delta t$ is the time step, $\Delta x$ is the mesh spacing, $u$ is the inflow velocity, and $C$ is the cell Courant number, which is used here to coordinate the mesh size and the time step. When $C$ is larger than 10, the calculation is easy to diverge and fail to provide a result. That is why the values of the mesh size and the time step have to be selected in a proper manner suitable for the calculation to be performed.

The time step is adjusted according to $C_{\text {lim }}$. Three different $C_{\text {lim }}$ values: $0.25,0.5,0.75$ were investigated in terms of their influence on the flooding problem. The flooding profiles obtained from these calculations are compared in Fig. 3.

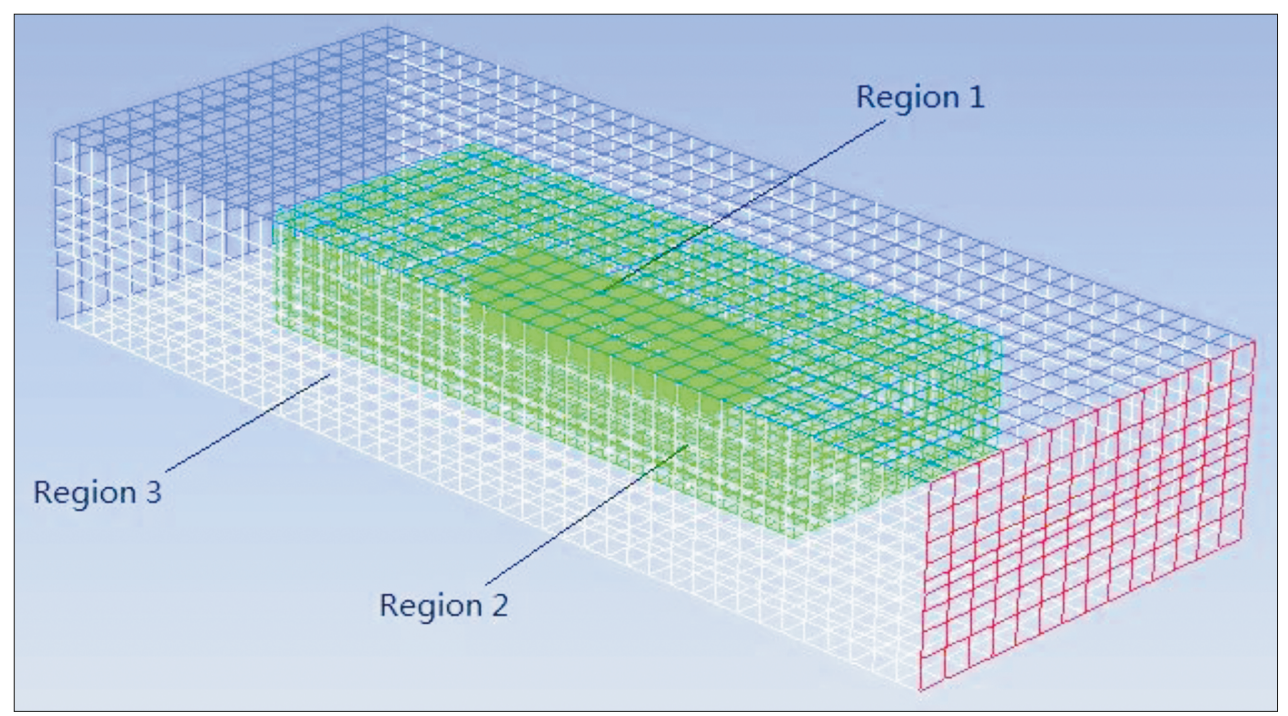

Fig. 2. Diagram of the computational domain 

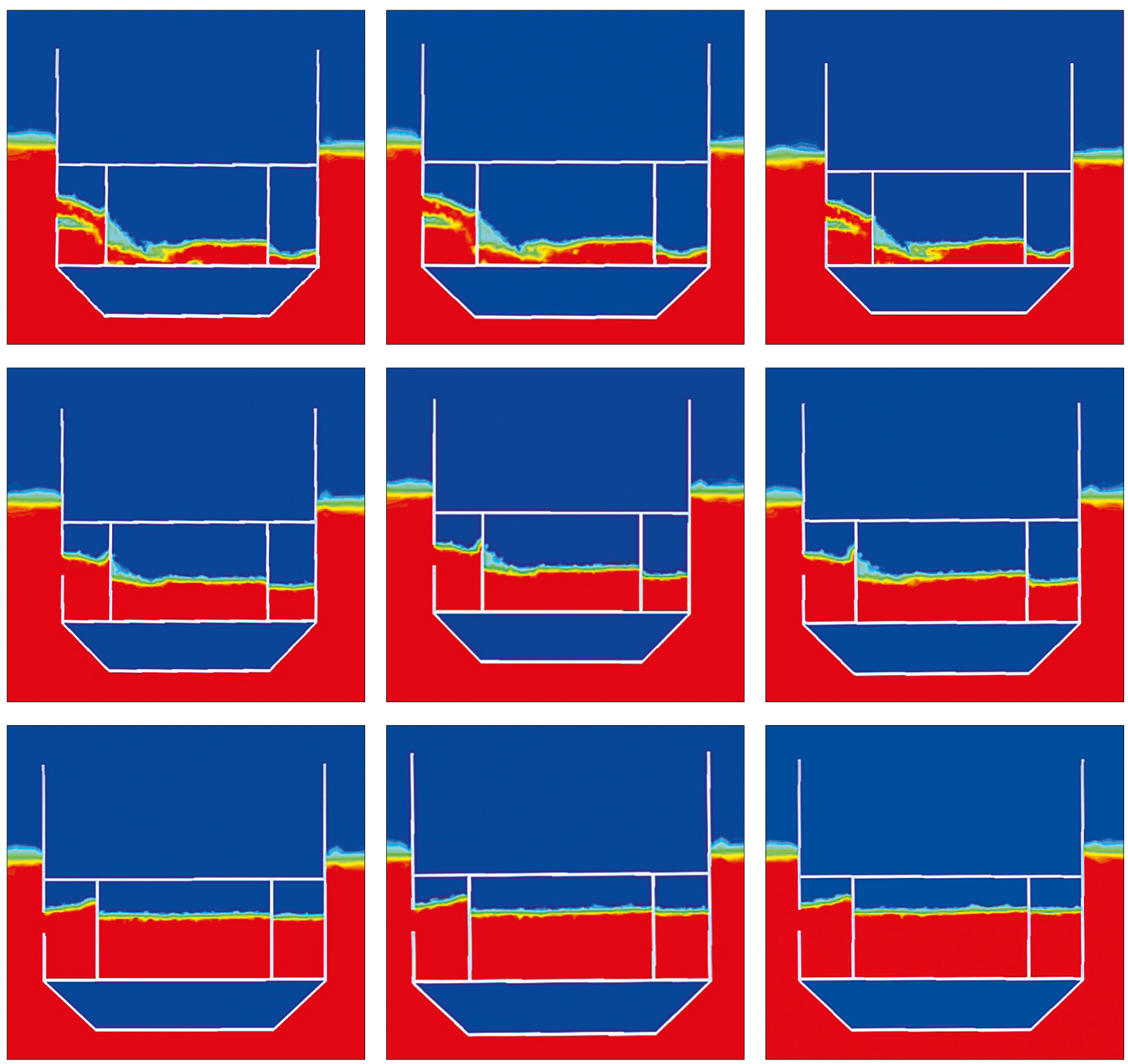

Fig. 3. Flooding process $(t=5 s, 10 s, 15 s)$ with different $C_{\text {lim }}$ values (left: 0.25 , mid: 0.5 , right: 0.75)

When the floodwater reaches the opposite side of the compartment, the flow becomes violent. However, even in that case, there is still good consistency in the motion of floodwater for these three $C_{\lim }$ values. The results show that the case $C_{\text {lim }}=0.5$ consumes relatively little computational resources, while still ensuring feasible numerical accuracy. Therefore, the limiting cell Courant number equal to 0.5 will be used throughout the simulation.

Normally, time steps between $0.001 \mathrm{~s}$ and $5 \mathrm{~s}$ are used in flooding simulations (Gao, 2012\&2013; Ruponen, 2014), to coordinate with the mesh size. This paper adopts the time step of 0.005 s to minimize the computation time, while preserving an acceptable accuracy. The flow calculation chart is shown in Fig. 4.

\section{NUMERICAL RESULTS}

\section{FLOATING BARGE FLOODING CASE}

This paper adopts the box-shaped barge model to verify the model test results of the flooding process. Ruponen (Ruponen, 2006) analyzed experimentally a series of model tests for a damaged barge in calm water, in order to provide experimental data for verification of numerical tools. The arrangement of the compartments in the barge is shown in Fig. 5, and its main particulars are provided in Table 1 . The connection hole dimensions are listed in Table 2. 


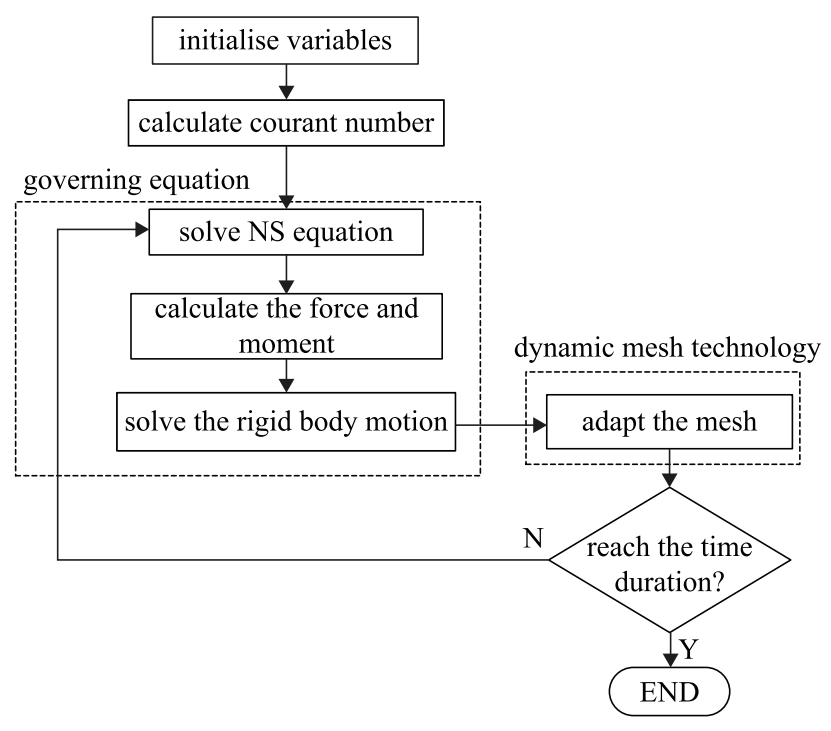

Fig. 4. Flow calculation chart

In Table 2, DB1-DB2 means the hole between tanks DB1 and DB2. The hole is round, and its diameter is $20 \mathrm{~mm}$. DB2-R21 means the hole connecting tanks DB2 and $\mathrm{R} 21$. It is rectangular, and its dimensions are $60^{\star} 40$. The following expressions are similar. The floodwater motion in the compartment is the key to the flooding process. The prediction accuracy significantly depends on the number of grid elements. In this paper, the appropriate size of mesh enables to keep the Courant number below the limit of 10 . The number of elements is listed in Table 3.

Considering the oscillation of the real flow field, in order to compare changes of the mass flux at the damaged opening during the initial flooding stage, three models:

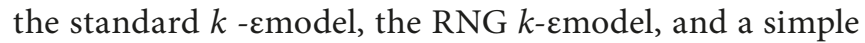
laminar model have been adopted. Fig. 6 shows the timehistory of mass flux change at the damaged opening. At the initial stage, the mass flux at the damaged opening increases quickly, and the tendency of changes presented by the three investigated models is similar. Compared with the other two models, the use of the simple laminar model can ensure
Tab. 1. Main data of the barge

\begin{tabular}{|c|c|}
\hline Parameter & Dimension \\
\hline Length of all (Loa) (m) & 4.00 \\
\hline Breadth (B) (m) & 0.80 \\
\hline Depth (D) (m) & 0.80 \\
\hline Draft (T) (m) & 0.50 \\
\hline Denter of gravity above base line $(\mathrm{KG})(\mathrm{m})$ & 0.278 \\
\hline Length of tank (m) & 0.7 \\
\hline Breadth of tank $(\mathrm{m})$ & 0.8 \\
\hline Height of tank $(\mathrm{m})$ & 0.8 \\
\hline Moment of inertia along x-axis $(\mathrm{Ixx})\left(\mathrm{kg} \mathrm{m}^{2}\right)$ & 176.0 \\
\hline Moment of inertia along y-axis $(\mathrm{Iyy})\left(\mathrm{kg} \mathrm{m}^{2}\right)$ & 2235.3 \\
\hline Moment of inertia along z-axis $(\mathrm{Izz})\left(\mathrm{kg} \mathrm{m}^{2}\right)$ & 2209.4 \\
\hline
\end{tabular}

Tab. 2. Main particulars of the barge model

\begin{tabular}{|c|c|}
\hline Location of tank & Connection hole dimension (mm) \\
\hline DB1-DB2 & $\mathrm{D}=20$ (round hole) \\
\hline DB2-R21 & $60 * 40$ \\
\hline R21-R21S & $20 * 200$ \\
\hline R21-R21P & $20 * 200$ \\
\hline R21-R11 & $\mathrm{D}=20$ (round hole) \\
\hline R21-R22 & $100 * 100$ \\
\hline R11-R12 & $100 * 100$ \\
\hline R12-R22 & $80 * 200$ \\
\hline
\end{tabular}

Tab. 3. Number of grid elements in different domains

\begin{tabular}{|c|c|c|c|c|c|}
\hline \multirow{2}{*}{ location } & \multicolumn{3}{|c|}{ region 1 } & \multirow{2}{*}{ region 2 } & \multirow{2}{*}{ region 3 } \\
\cline { 2 - 4 } & $\begin{array}{c}\text { eight } \\
\text { cabins }\end{array}$ & $\begin{array}{c}\text { enclosed } \\
\text { cabin }\end{array}$ & $\begin{array}{c}\text { adjacent } \\
\text { hull }\end{array}$ & & \\
\hline number & 556489 & 125623 & 934562 & 236320 & 95782 \\
\hline
\end{tabular}

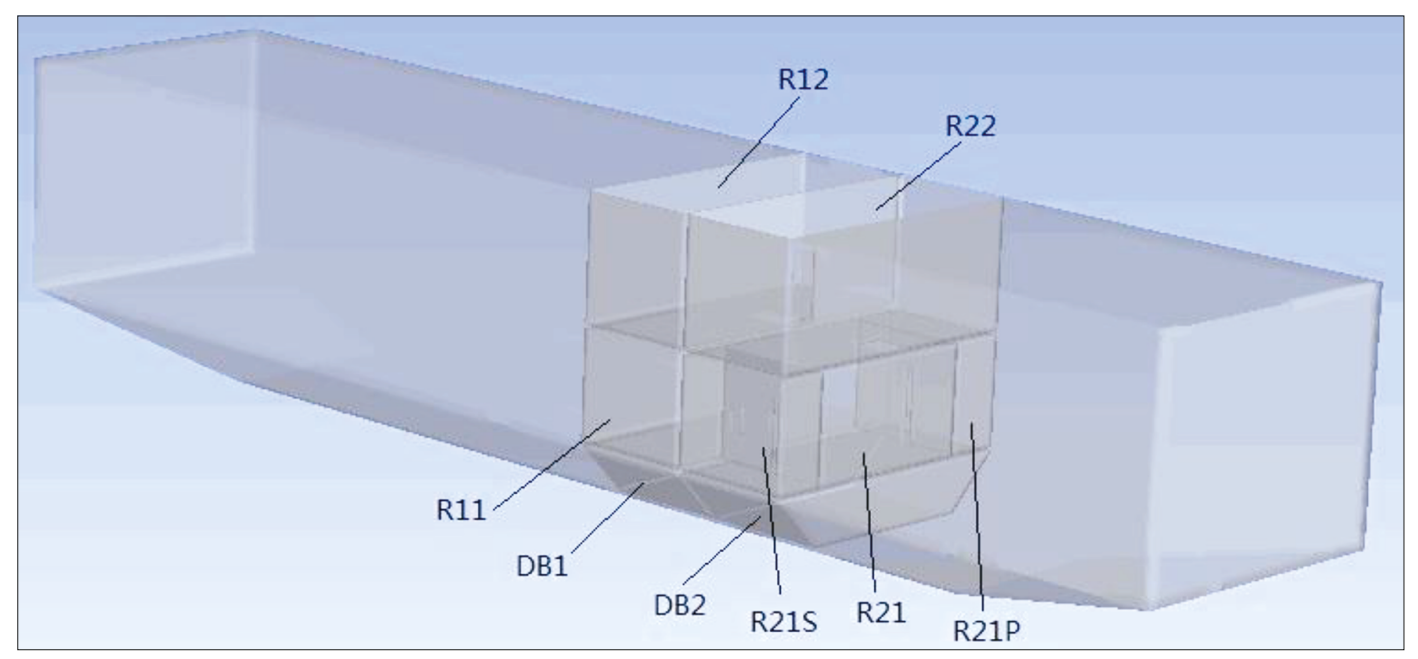

Fig. 5. Diagram of the damage barge model 
acceptable numerical accuracy while consuming relatively little computational resource. Thus, this paper adopts the laminar model to conduct the simulation.

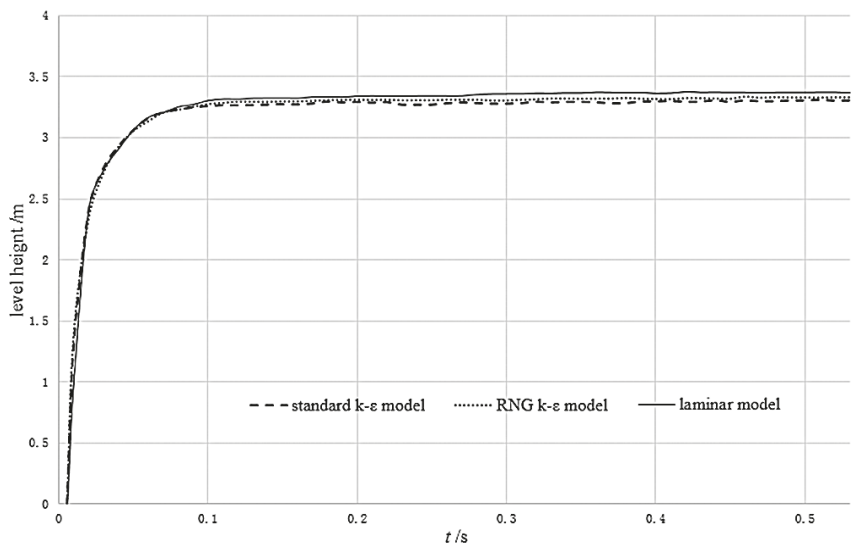

Fig. 6. Time-history of mass flux change at damaged opening

The simulation process ends at 180s. It uses $600 \mathrm{CPU}$ hours for the flooding. The flooding water in the compartments is shown in Fig. 7. In general, the computed floodwater characteristics are in accordance with the experimental results. During the initial several seconds, the flooding is asymmetrical with respect to the central axis, but the entire flooding process appears to be symmetrical about the central axis. The external water floods
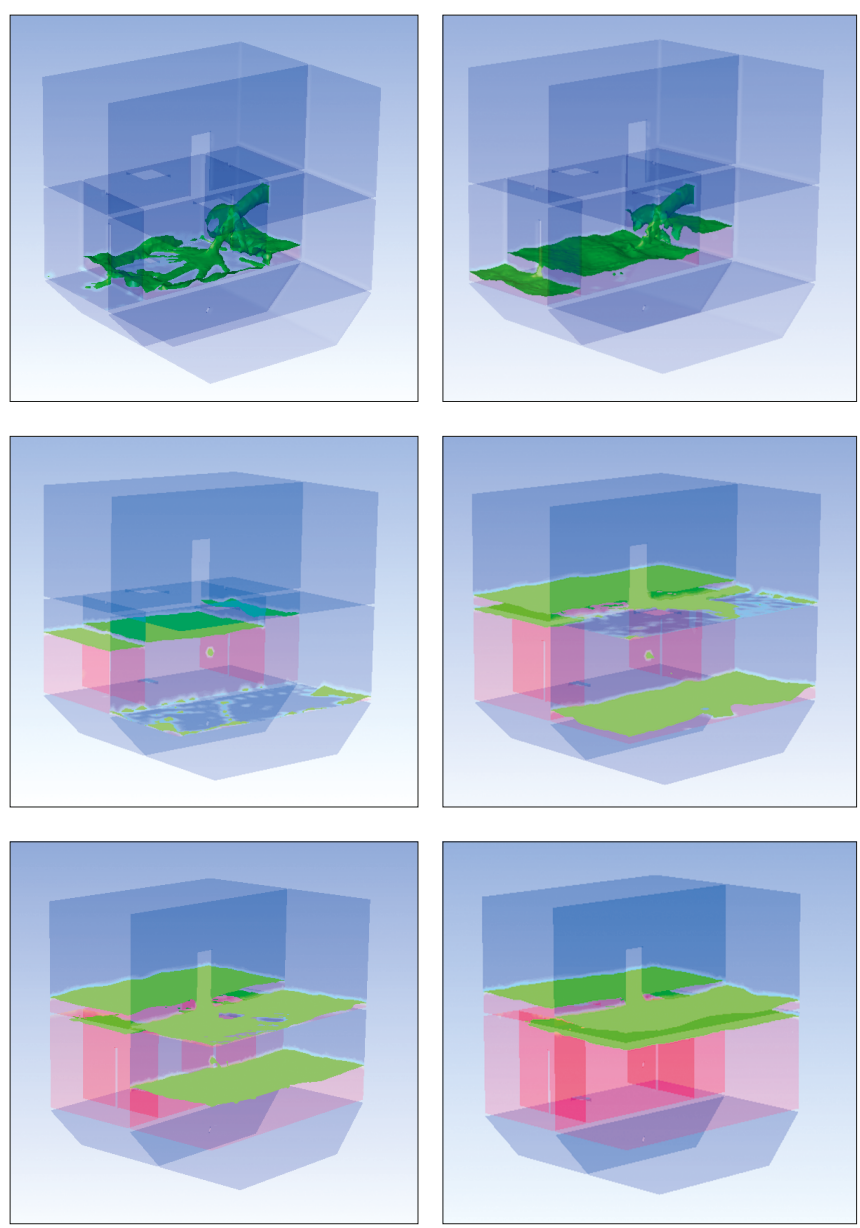

Fig. 7. Internal water motion at different stages $(t=1 \mathrm{~s}, 4 s, 15 s, 32,52 s, 84 s)$ into R21S violently via the damaged opening and its level increases rapidly in the compartment. The floodwater sprays straightly into R21 and spreads throughout the compartment promptly, as the damaged opening is collinear with the internal opening that connects R21S with R21. As the internal openings connecting the compartments are large, the floodwater flows through R21, R21P and R21S without obvious blockage. The water height in these compartments rises rapidly. After 15s, the flooding process seems to become almost symmetrical.

Figs. 8-10 compare the water levels obtained in the numerical simulation (Gao, 2011) and the experiment (Ruponen, 2006). Since the difference between the internal and external water heights decreases, the water level initially rises rapidly and then slows down. The difference between the results of the numerical simulation and the experiment decreases at the final flooding stage. When the water level in the compartments is approximately the same as that outside the barge, the flooding process terminates at almost $180 \mathrm{~s}$.

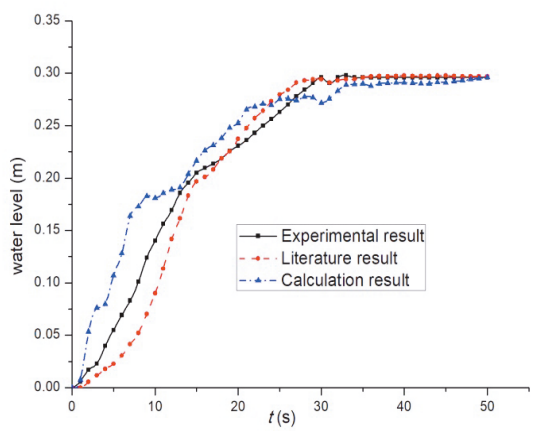

Fig. 8. Comparing time-histories of water level change in R21S

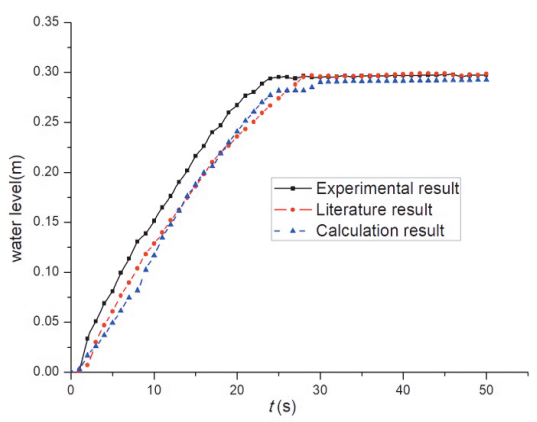

Fig. 9. Comparing time-histories of water level change in R21

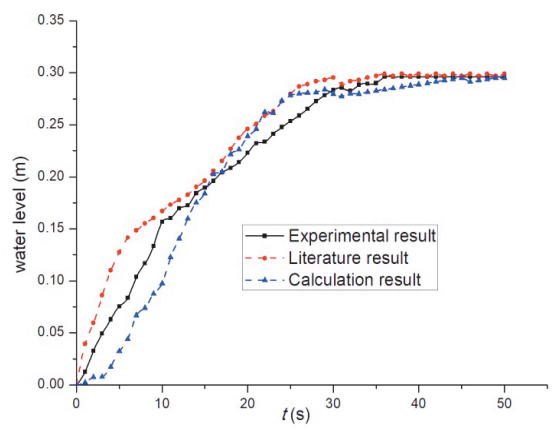

Fig. 10. Comparing time-histories of water level change in R21P 


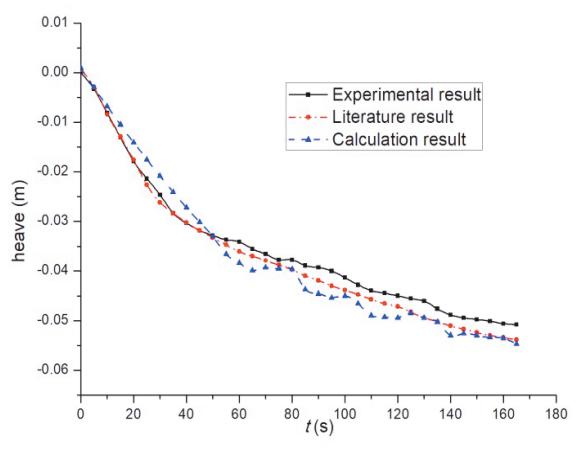

Fig. 11. Time histories of heave motion of the barge

The barge motions are shown in Figs. 11-12. The calculated results are compared with the experiment and the data available in the literature (Ruponen, 2006; Gao, 2011). Firstly, the barge sinks rapidly due to drastic water entry. Once the tanks R21, R21P and R21S are fully filled, the sinking of the barge becomes slower. The comparison indicates that the computed results are in accordance with the experiment.

This simulation calculation assumes six degrees of freedom of the ship, and the model test is performed for the fully free floating state. The flooding process is initially violent, then the barge is forced to sink and roll rapidly. In the final stages, the flooding water moves smoothly, and the barge becomes quasistatic. According to the reference (Ruponen, 2007), the roll motion of the barge model during the flooding process can be neglected, which is validated in this simulation and omitted in the result. The elevations of the liquid level in the abovementioned three compartments coincide well, which shows that the heaving motion of the ship has little influence on the flooding process of these three compartments. Judging from comparison with the available data, the results of the CFD technology based simulation turn out accurate, and the acceptable simulation accuracy level is obtained, which proves that the selected setting options and mesh parameters are feasible.

\section{RECTANGULAR CABIN MODEL FLOODING CASE}

The rectangular cabin model is shown in Fig. 13, and its dimensions are given in Table 4.

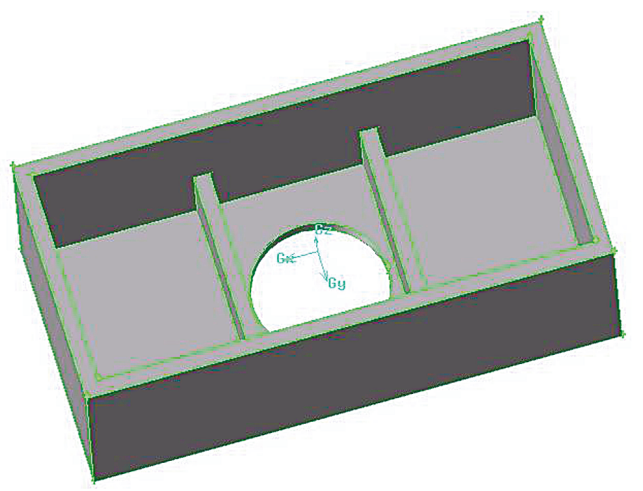

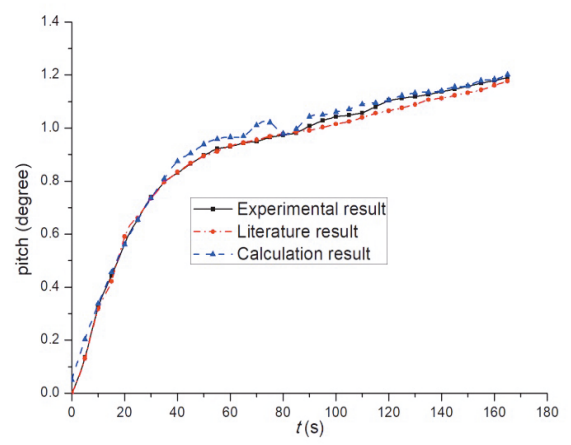

Fig. 12. Time-histories of pitch motion of the barge

Tab. 4. Main particulars of the rectangular cabin model

\begin{tabular}{|c|c|}
\hline Parameter & Dimension (mm) \\
\hline Length & $\mathrm{L}=350(\mathrm{~mm})$ \\
\hline Width & $\mathrm{B}=170(\mathrm{~mm})$ \\
\hline Height & $\mathrm{H}=130(\mathrm{~mm})$ \\
\hline Damaged opening & $\mathrm{D}=90(\mathrm{~mm})$ \\
\hline Thickness & $10(\mathrm{~mm})$ \\
\hline Mass & $3.225(\mathrm{~kg})$ \\
\hline
\end{tabular}

Fig. 14 compares the simulation results recorded at different times $(\mathrm{t}=0.14 \mathrm{~s}, 0.4 \mathrm{~s}, 0.54 \mathrm{~s})$, with those presented for $3 \mathrm{DSPH}$ in reference (Cao, 2013). The model experiences the heaving motion, mainly at the initial flooding stage, when a large amount of water floods into the model clapboard. After 0.14s, the buoyancy is increased during the falling process, and the baffles around the damaged opening block the water inflow into the model. At $0.4 \mathrm{~s}$, the model starts to rise, and the water begins to enter into the model. At $0.55 \mathrm{~s}$, both sides of the baffles are flooded, and the model continues to fall. It is noteworthy that the same trends can be found in the numerical and experimental results.

Changes of vertical center of gravity and vertical velocity acquired from the simulation and the experiment are compared in Fig. 15 and Fig. 16, which illustrate the coupling movement of the damaged model and flooding water within

Fig. 13. Model diagram (left: cabin model, right: mesh) 

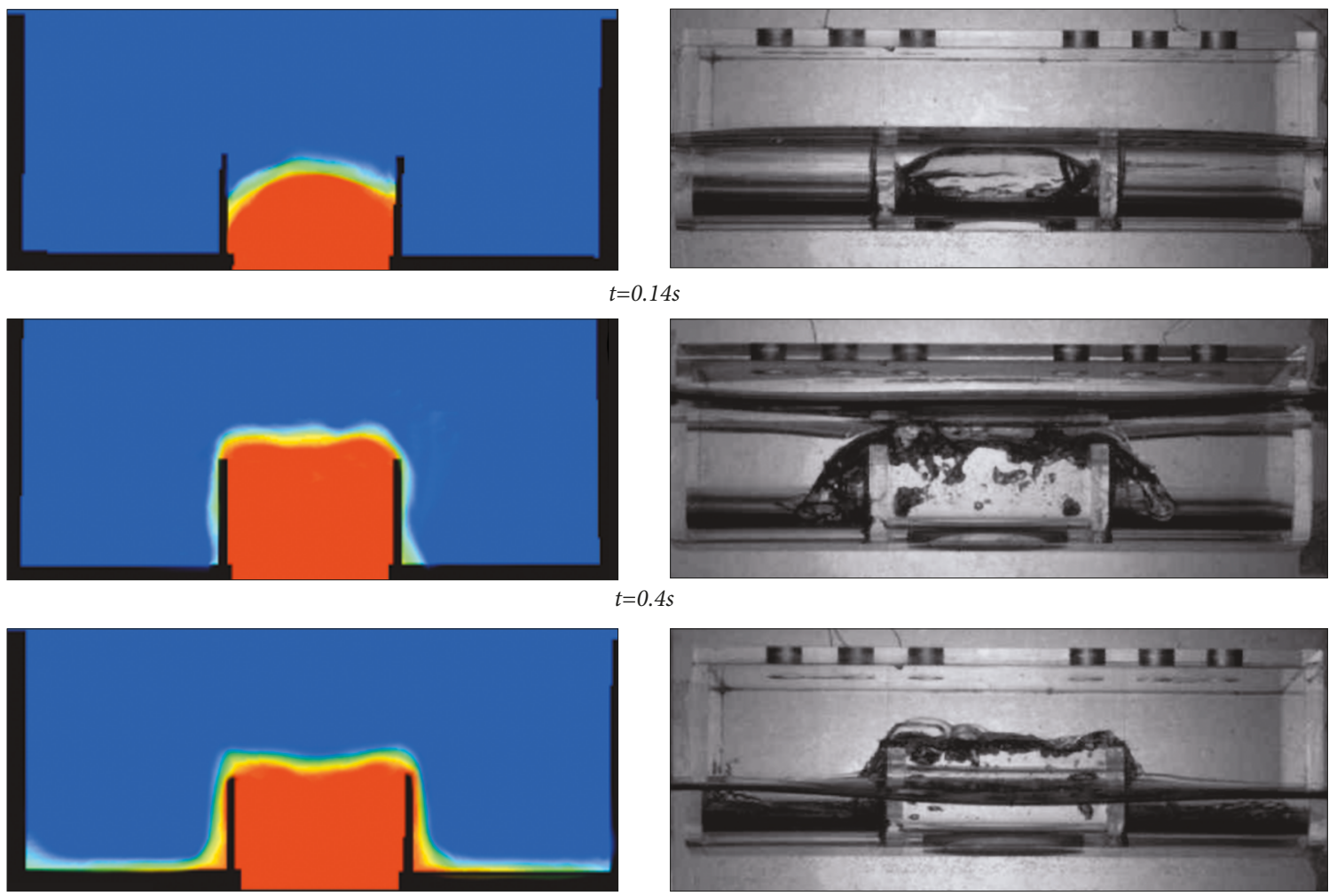

$t=0.54 \mathrm{~s}$

Fig. 14. Flooding process stages at different times (left: numerical simulation, right: experiment)

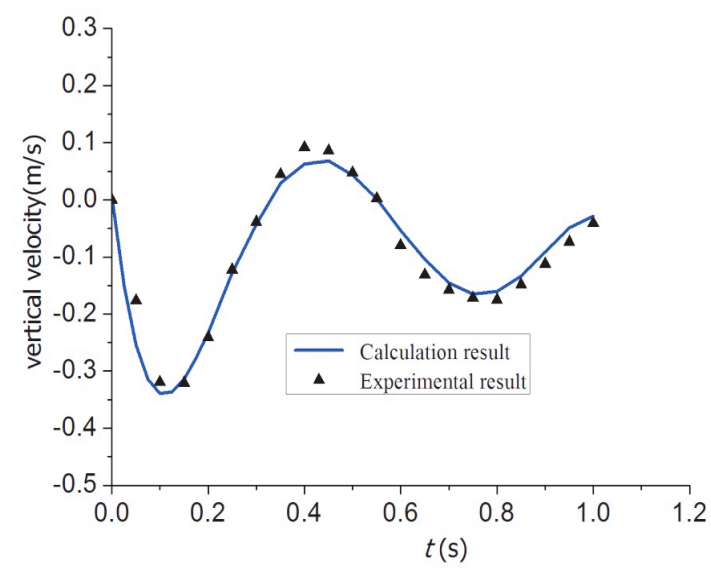

Fig. 15. Time-history of vertical velocity change

1 second. This comparison reveals that the results obtained using the above two methods coincide well with each other, and the discrepancies between them during the flooding process are small. Thus, the numerical results obtained using the present mesh for the examined case can be considered satisfactory and useful as both the reference for ship's flooding process forecasting, and a tool in rescue actions.

\section{CONCLUSION}

This paper has adopted the NS solver with the VOF model to simulate the flooding of a box-shaped barge. To validate its performance, the flooding study of a rectangular cabin

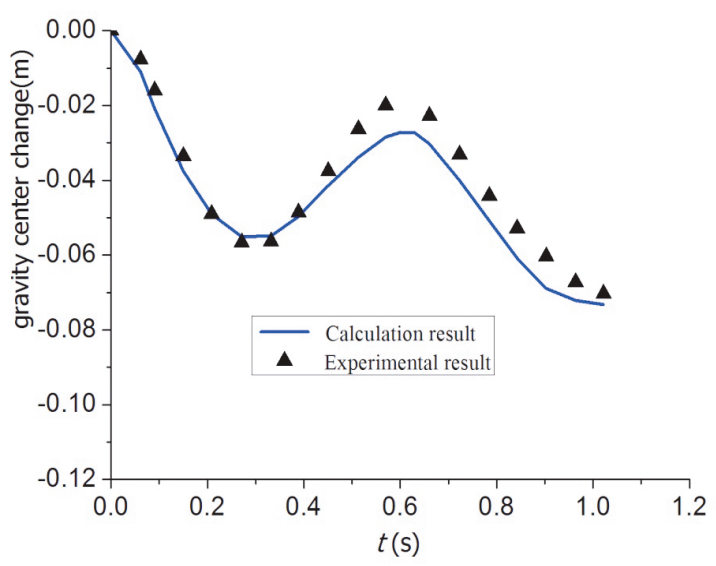

Fig. 16. Time-history of gravity center change

model was also carried out. The research has shown that the developed method is effective in predicting the coupled dynamic characteristics of the ship with floodwater. The VOF method is feasible for capturing the free surface during the flooding process. The dynamic mesh strategy is introduced to consider the motions of the ship. For the floating barge, the flooding process is violent during the initial stage, while in the intermediate and final stages the barge becomes quasi-static and the flooding flow moves smoothly. For the rectangular model, the simulation results are in good accordance with the experiment, which provides some guidance for ship flooding. Also, on the basis of this validation, the numerical research of flooding of a certain damaged warship in beam wind and wave conditions will be carried out in the time-domain. 


\section{ACKNOWLEDGEMENTS}

This paper was supported by the National Natural Science Foundation of China $(51509124,51681340360)$ and the Natural Science Fund of Shandong Province (ZR2015PE010), within the framework of the Hi Tech ship project of the Ministry of industry and technology entitled: "Study on second generation intact stability criteria and direct assessment technique of pure loss of stability 2016" [26]. The authors would like to extend their sincere gratitude to the above organizations.

\section{REFERENCES}

1. Cao X Y, Ming R F, Zhang A M. Flooding characteristic simulation study of damaged ship based on 3D SPH method. 16th Academic Symposium on China's marine (Shore) Engineering, 2013, Dalian, China.

2. D.K. Lee, S.Y. Hong, G.-J. Lee. Theoretical and experimental study on dynamic behavior of a damaged ship in wave. Ocean Engineering, 2007, 34: 21-31.

3. Gao Z L, Vassalos D, Gao Q X. Numerical simulation of water flooding into a damaged vessel's compartment by the volume of fluid method. Ocean Engineering, 2010, 37: 1428-1442.

4. Gao Q X, Vassalos D. Numerical study of damage ship hydrodynamics. Ocean Engineering, 2012, 55: 199-205.

5. Gao Z L, Gao QX, Vassalos D. Numerical study of a damaged ship flooding in beam seas. Ocean Engineering, 2013, 61: 77-87.

6. Gao Z L, Gao Q X, Vassalos D. Numerical simulation of flooding of a damaged ship. Ocean Engineering, 2011, 38: 1649-1662.

7. IMO. Explanatory Notes to the SOLAS Chapter II-1 Subdivision and Damage Stability Regulations, Resolution MSC. 2008, 281(85).

8. Lemoine, L., Mahé, F., Morisset, N., Bertin, R. Interpretation and design implications of probabilistic damage stability regulation, Proceedings of the 13th International Ship Stability Workshop, 2013: 214-227, Brest, France.

9. Li Y M, Duan W Y, Jin Y L et al. Flooding Process of Damaged Ship Based on CFD. Shipbuilding of China, 2016, 57(2): 149-163.

10. Lyu Z W, Ma K, Liu F. Military ship’s subdivision optimization for reinforcement of anti-wind capacity after damage. Journal of Marine Science and Technology, 2015, 20: 579-589.

11. Manderbacka, T., Mikkola, T., Ruponen, P., Matusiak, J. Transient response of a ship to an abrupt flooding accounting for the momentum flux. Journal of Fluids Structure, 2015, 57: 108-126.

12. Manderbacka, T., Ruponen, P. The impact of the inflow momentum on the transient roll response of a damaged ship. Ocean Engineering, 2016, 120: 346-352.

13. Ruponen, P., Queutey, P., Kraskowski, M., Jalonen, R., Guilmineau, E. On the calculation of cross-flooding time. Ocean Engineering, 2012, 40: 27-39.

14. Ruponen, P., Pulkkinen, A., Laaksonen, J. A method for breach assessment onboard a damaged passenger ship. Applied Ocean Research, 2017, 64: 236-248.

15. Ruponen, P. On the effects of non-watertight doors on progressive flooding in a damaged passenger ship. Ocean Engineering, 2017, 130: 115-125.

16. Ruponen, P. Adaptive time step in simulation of progressive flooding. Ocean Engineering, 2014, 78: 35-44.

17. Ruponen, P. Model tests for the progressive flooding of a boxshaped barge. Helsinki University of Technology, Ship Laboratory Report M-292, 2006.

18. Ruponen, P. Progressive flooding of a damaged passenger ship. Helsinki University of Technology, Helsinki, Finland, 2007.

19. Ruponen, P., Sundell, T., Larmela, M. Validation of a simulation method for progressive flooding. International Shipbuilding Progress, 2007, 54: 305-321.

20. Santos, T.A., Winkle, I.E., Guedes Soares, C. Time domain modelling of the transient asymmetric flooding of Ro-Ro ships. Ocean Engineer. 2002, 29: 667-688.

21. Schreuder, M., Hogström, P., Ringsberg, J.W., Johnson, E., Janson, C.-E. A method for assessment of the survival time of a ship damaged by collision. Journal of Ship Research, 2011, 55 (2): 86-99.

22. Tiago A. Santos, C. Guedes Saores. Study of damaged ship motions taking into account floodwater dynamics. Journal of Marine Science and Technology, 2008, 13(3): 291-307.

23. Tiago A. Santos, C. Guedes Saores. Numerical assessment of factors affecting the survivability of damaged ro-ro ships in waves. Ocean Engineering, 2009, 36(11): 797-809.

24. Vassalos, D., Ikeda, Y., Jasionowski, A., Kuroda, T. Transient Flooding on Large Passenger Ships. Proceedings of the 7th International Ship Stability Workshop, 2004, Shanghai, China.

25. Ypma, E., Turner, T. An approach to the validation of ship flooding simulation models. Proceedings of the 11th International Ship Stability Workshop, 2010, Wageningen, The Netherlands. 


\section{CONTACT WITH THE AUTHORS}

Hu Li-Fen

e-mail:hlfgfff2008@aliyun.com

Qi Huibo

e-mail:499427729@qq.com

Li Wubin

e-mail:277481485@qq.com

Chen Shude

e-mail:759817781@qq.com

Ludong University, Transporation School

HONGQI Middle Road

264025 Yantai

China

Li Yuemeng

e-mail:421022889@qq.com

Ludong University, Ulsan Ship and Ocean College

HONGQI Middle Road

264025 Yantai

China 